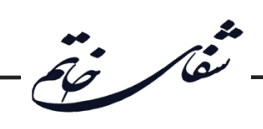

\title{
The Evaluation of Brain Derived Neurotrophic Factor and Working Memory in Valproic Acid Animal
}

\section{Model of Autism}

\author{
Zahra Borzou ${ }^{1,2}$, Mohammad Amin Edalatmanesh ${ }^{\text {* }}$ \\ ${ }^{1}$ Department of Physiology, College of Sciences, Shiraz Branch, Islamic Azad University, Shiraz, Iran \\ ${ }^{2}$ Department of Physiology, College of Sciences, Fars Science and Research Branch, Islamic Azad University, Fars, Iran
}

\section{A BSTRACT}

Introduction: Autism, a complex neurodevelopmental disorder, is characterized by social impairments, communication difficulties, as well as restricted, repetitive, and stereotyped patterns of behavior. Changes in serum level of brain-derived neurotrophic factor (BDNF) play a role in autism etiology. However, the serum levels and the mechanism of action of BDNF in autism are needed to be elucidated. Therefore, this study was aimed to determine the serum levels of BDNF and its relation with working memory in valproic acid animal model of autism. Materials and Methods: Female Sprague Dawley rats were divided into two Phosphate-Buffered Saline receiver (PBS) and Valproic Acid receiver (VPA) groups. The pregnant rats were recieved VPA ( $500 \mathrm{mg} / \mathrm{kg} / \mathrm{ip}$ ) or PBS for 12.5 days after gestation. We evaluated the offspring in postnatal days 30 and 60 . To measure changes in working memory and the periodic behaviors of the animals, Y maze test was used. In addition, the serum levels of BDNF were determined by ELISA method. Results: Increased alteration behavior was observed in Y-maze test among offspring received VPA group compared to control rats. The serum levels of BDNF in VPA rats were significantly higher than PBS group. Conclusion: BDNF increases accompanied by enhancement of periodic behaviors in VPA rats suggested a crucial role of this protein in working memory of autistic individuals.

\section{Key words:}

1. Autistic Disorder

2. Valproic Acid

3. Memory, Short-Term

* Corresponding Author: Mohammad Amin Edalatmanesh

E-mail:amin.edalatmanesh@gmail.com 


\title{
بررسى فاكتور نوروتروفيك مشتق از مغز و حافظةٌ كارى در مدل حيوانى اوتيسم القاء شده با واليروئيك اسيد
}

\author{
زهرا برزو r'، محمد امين عدالت منش" \\ اتروه فيزيولوزى، دانشكده علوم، واحد شيراز، دانشعاه آزاد اسلامى، شيراز، ايران \\ זَّروه فيزيولوزى، دانشكده علوم، واحد علوم و تحقيقات فارس، دانشگاه آزاد اسلامى، فارس، ايران
}

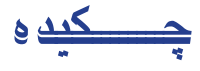

مقدمه: اوتيسم، يك اختلال تكاملى -عصبى ييجيده است كه توسط اختلالات اجتماعى، مشكلات

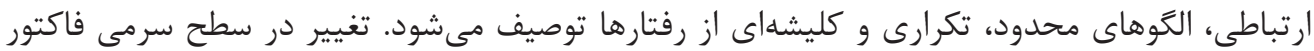

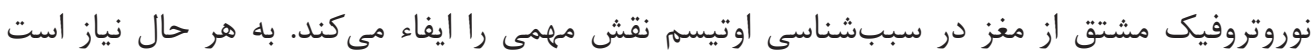

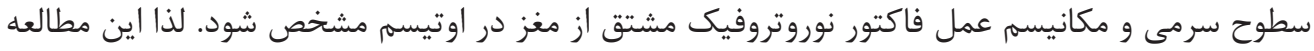

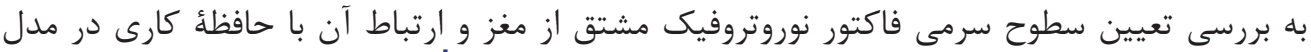

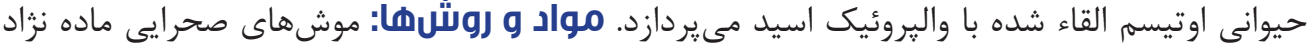

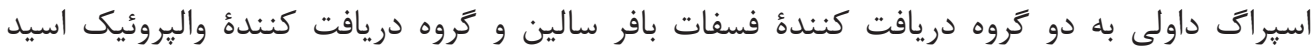

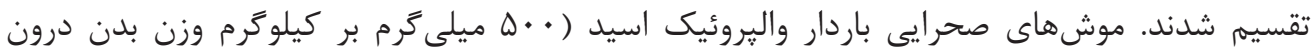

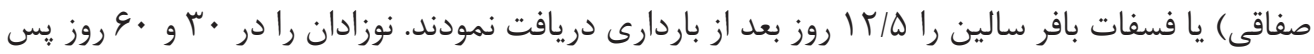

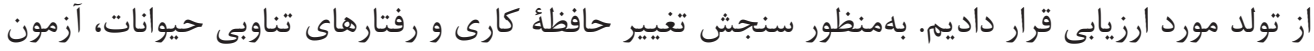

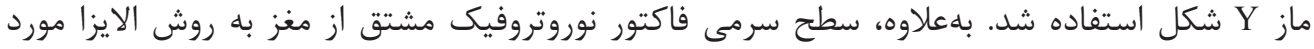

كليد وازهها:

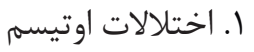

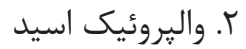

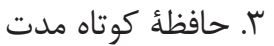

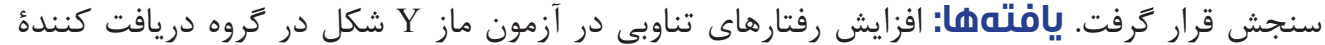

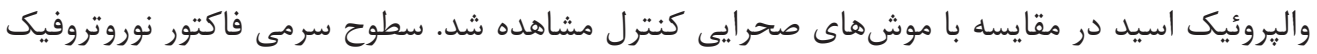

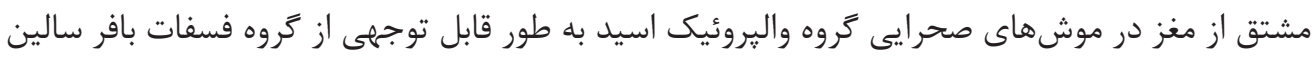

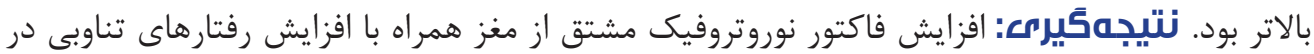

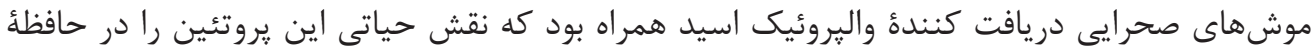

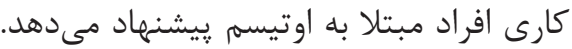




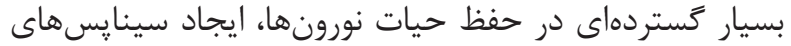

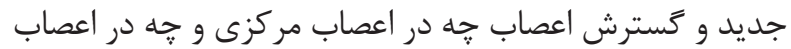

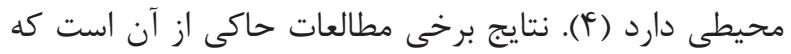

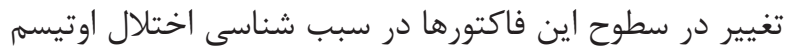

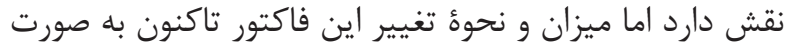

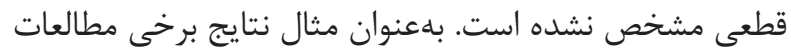

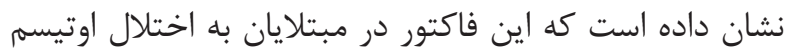

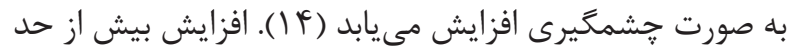

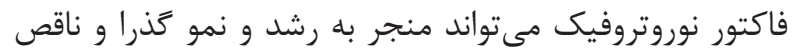

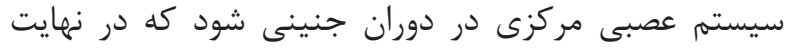
مىتواند يكى از علل اوتيسهم را بيان كند. دروان جنيني

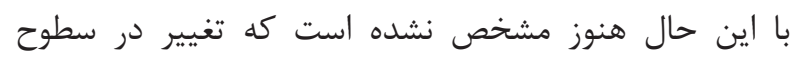

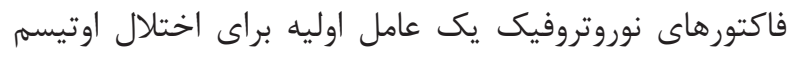

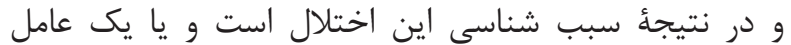

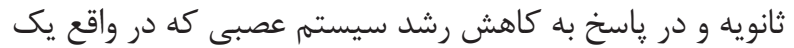

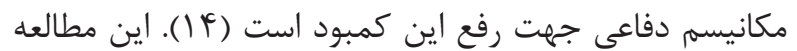

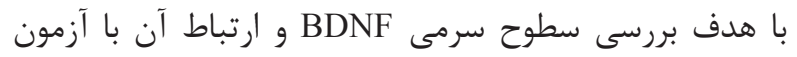

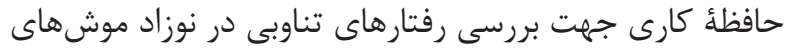
صحرايى مبتلا به اوتيسم صورت كرفتئه راست

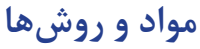

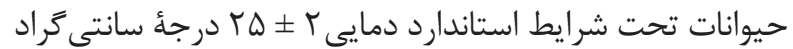

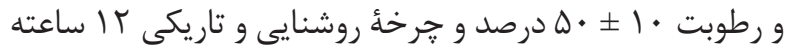

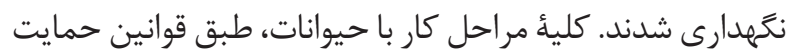

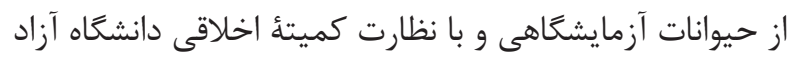

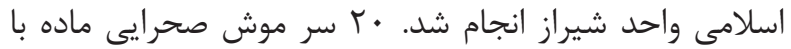

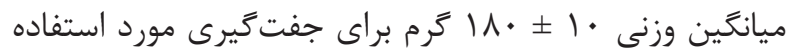

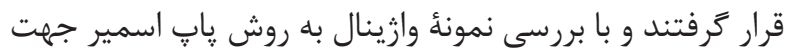

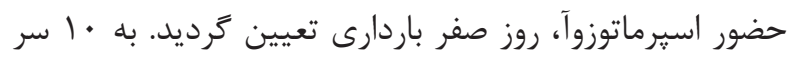

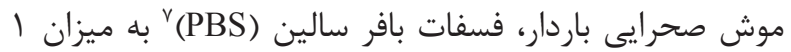

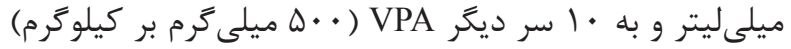

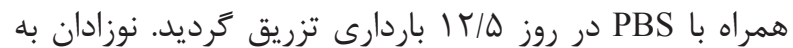

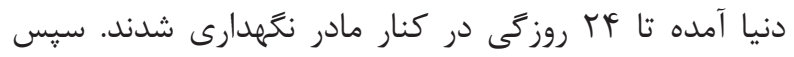

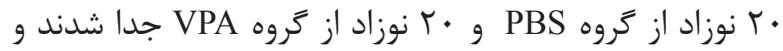

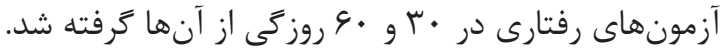

\section{آزمون ماز Y شكل: ارزيابى حافظةُ كارى}

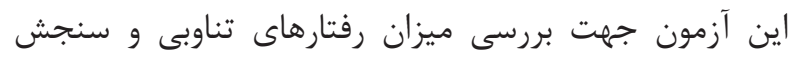

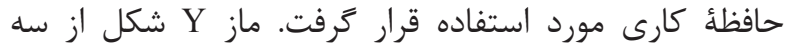

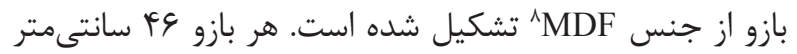

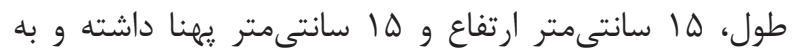

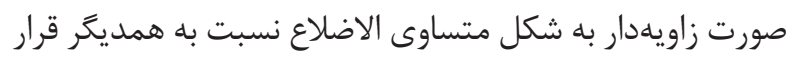

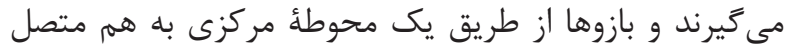

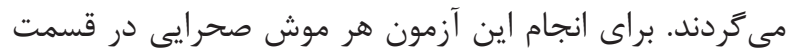

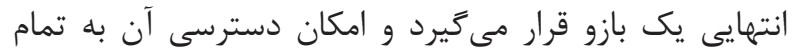

\footnotetext{
${ }^{1}$ Valproic acid

${ }^{2}$ Rats

${ }^{3}$ Brain-derived neurotrophic factor

${ }^{4}$ Nerve growth factor
}

اوتيسه يك اختلال تكاملى -عصبى است كه با ناهنجارىهاى

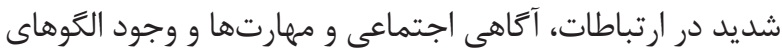

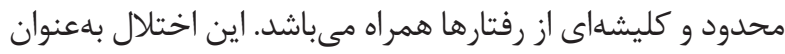

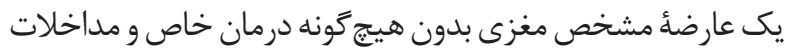

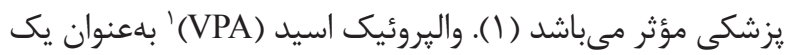

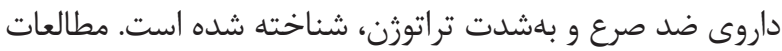

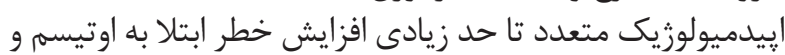

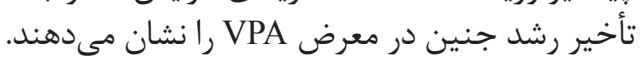

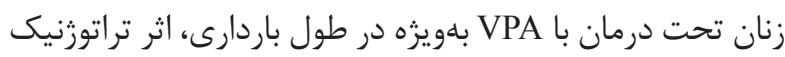

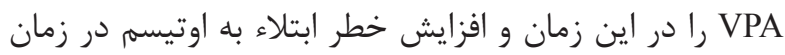

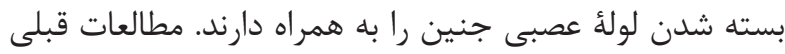

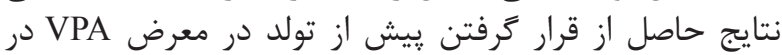

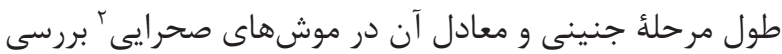

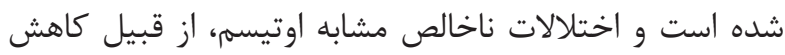

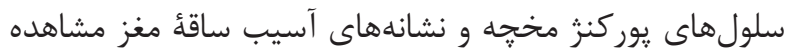

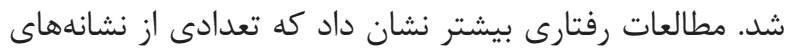

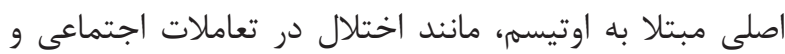

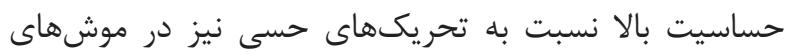

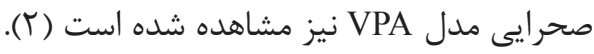

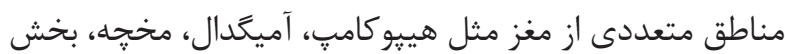

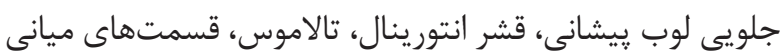

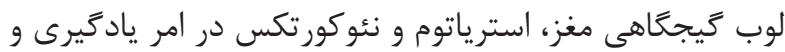

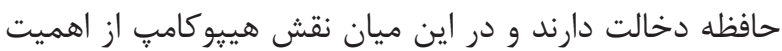

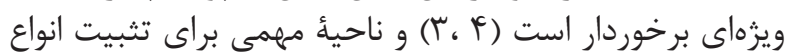

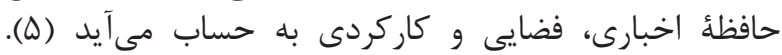

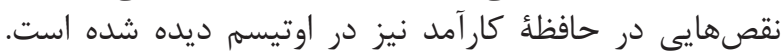

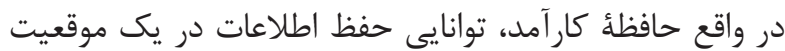

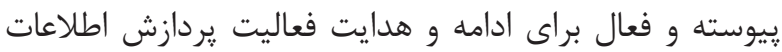

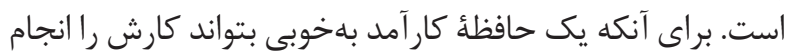

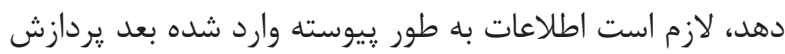

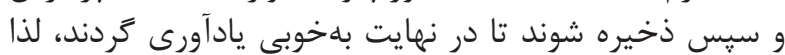

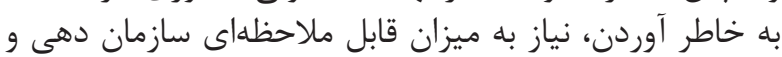
يردازش اطلاعات دارد (• (1-9).

نوروتروفينها (خانوادهاى از فاكتورهاى رشد عصبى)، نقشهي رهاى

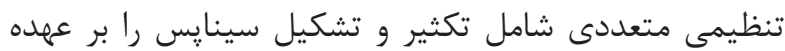

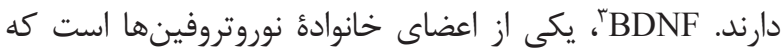

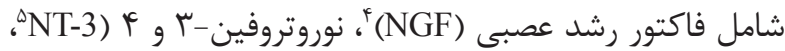

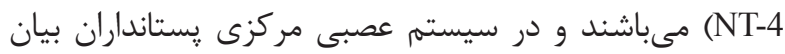

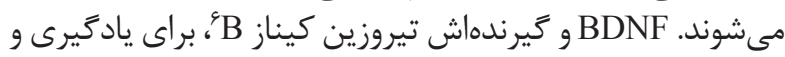

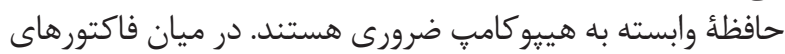

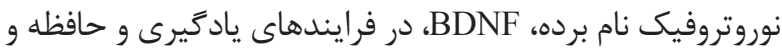

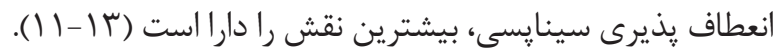

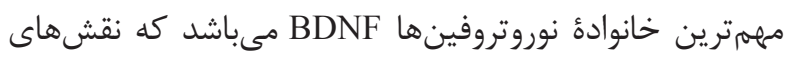

\footnotetext{
${ }^{5}$ Neurotrophin-3

${ }^{6}$ Tyrosine kinase B

${ }^{7}$ Phosphate buffered saline

${ }^{8}$ Medium-density fibreboard
} 


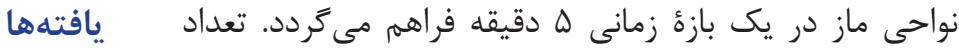

آزمون ارزيابى حافظةُ كارى

نتايج حاصل از آزمون ماز Y جهت برائ برسى ميزان رفتارهاى

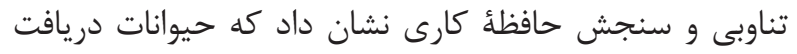
كننده

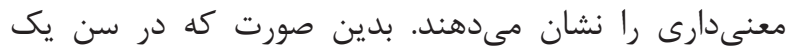

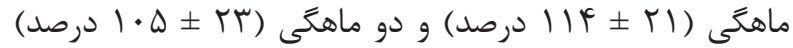

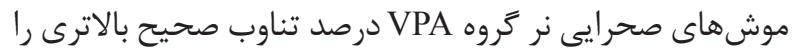

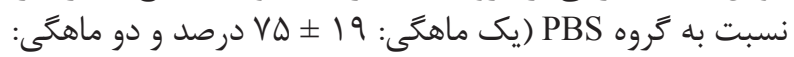

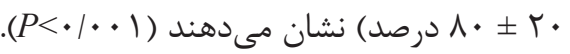

در جنس ماده در سن يك ماهگیى اختلاف معنى دارى بين دو

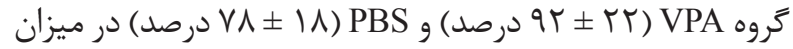

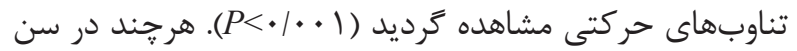

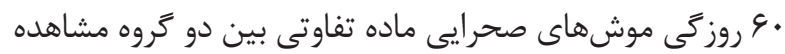

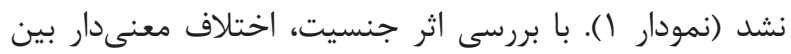

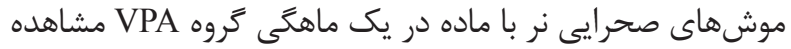

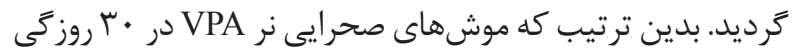

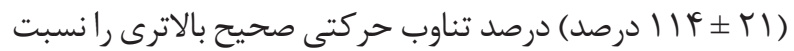
به جنس ماده (Y

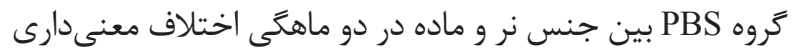

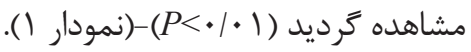

در بررسى اثر سن، اختلاف معنى دارى در جنس نر مشاهده

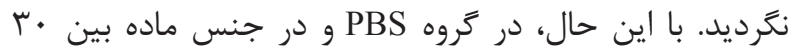

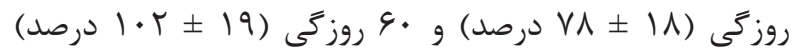

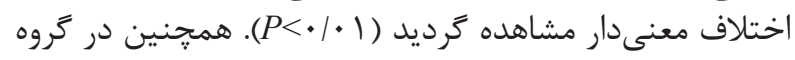
VPA

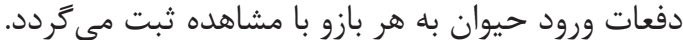

ورود هر حيوان به بازو زمانى است كه ياهاى عقبى حيوان

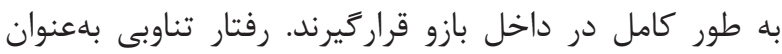

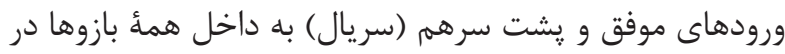

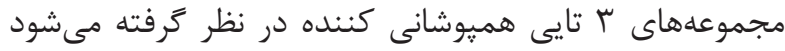

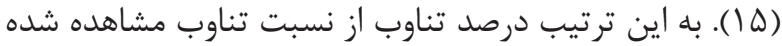

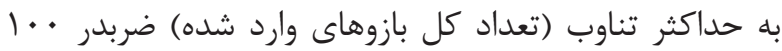

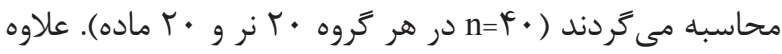

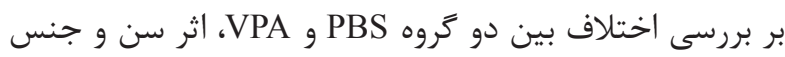

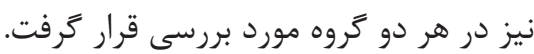

آزمون بيوشيميايى سنجش سطح سرمى BDNF

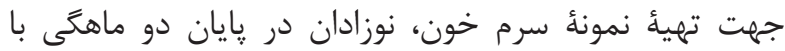

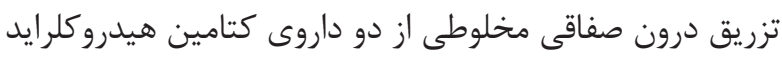

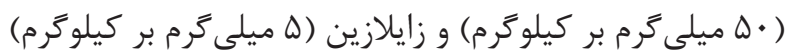

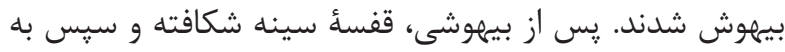

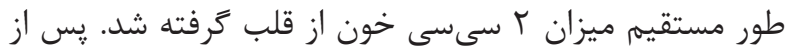

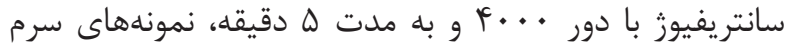

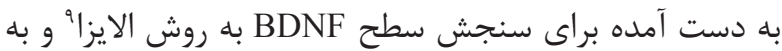

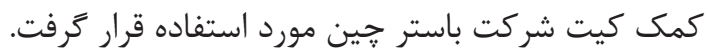

$$
\text { آناليز آمارى }
$$

تجزيه و تحليل آمارى بين گَروههاى مختلف با استفاده از نرم افزار

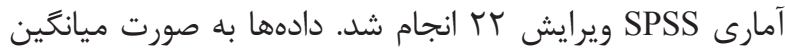

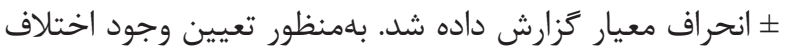

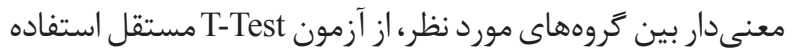

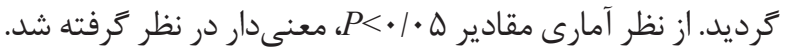

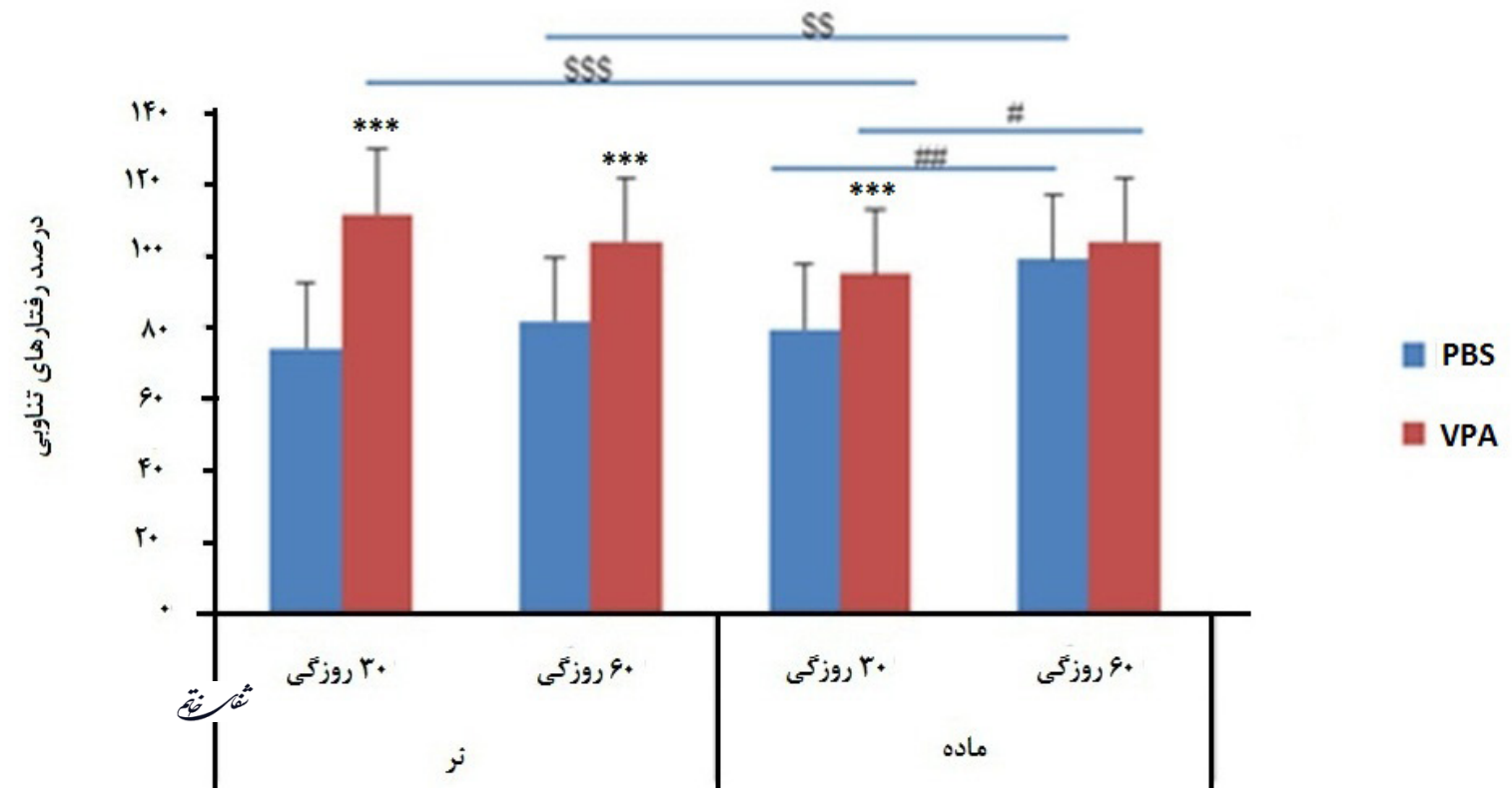

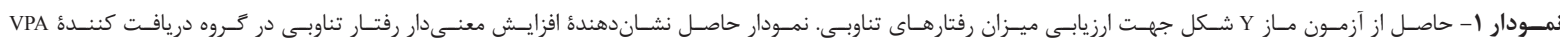

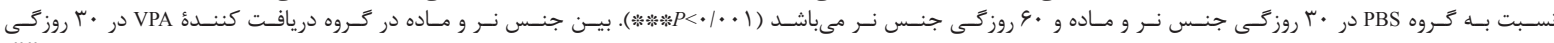

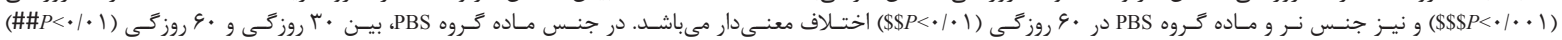

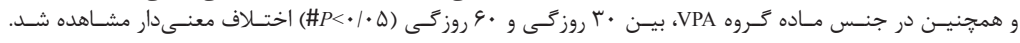




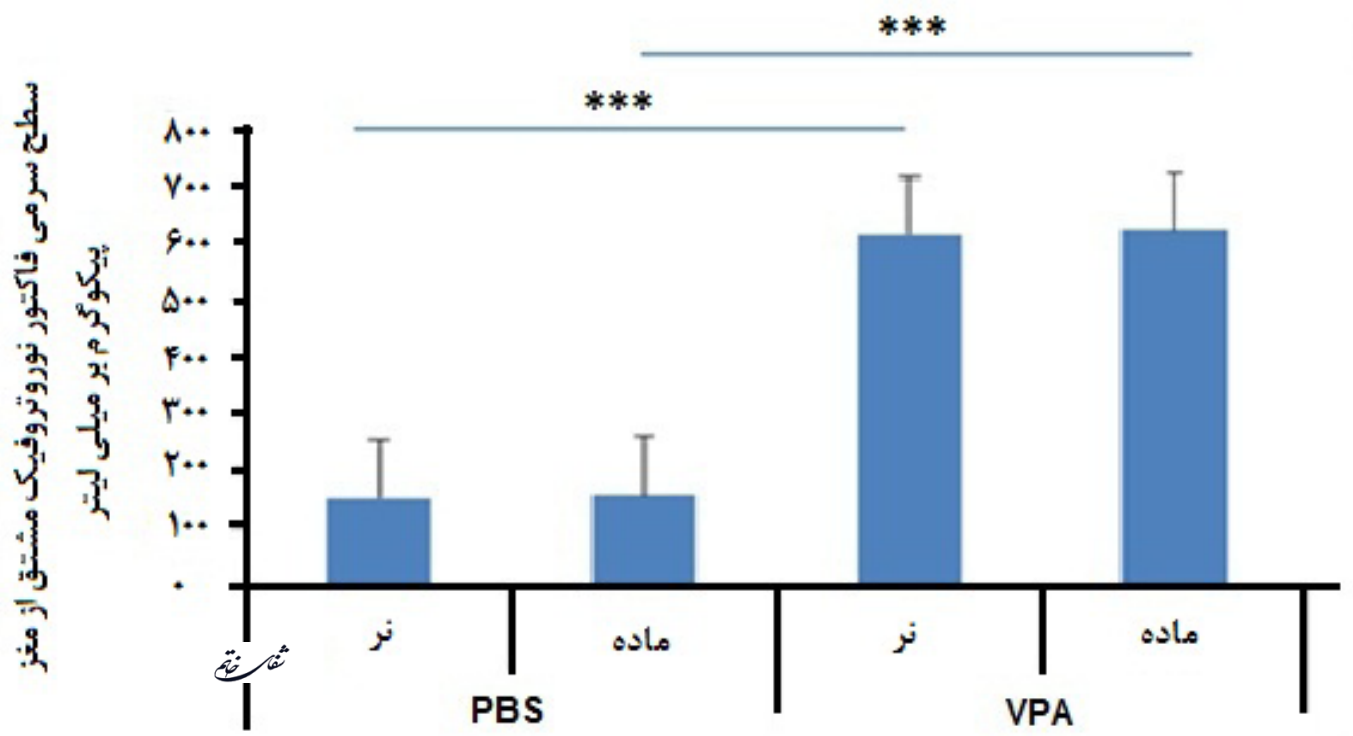

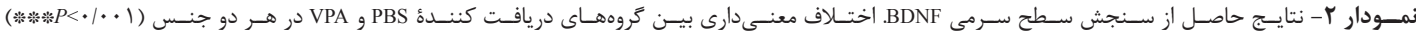

NهDA است. اين كيرندهها يروتئينهايى هستند كه شدت

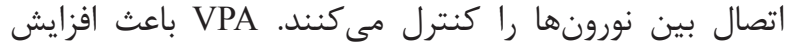

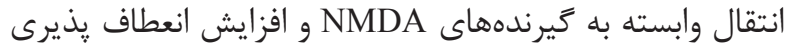

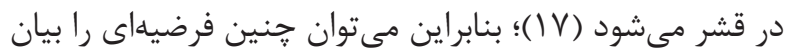
كرد كه در موشهاى صحر مايى اوتيستيك"

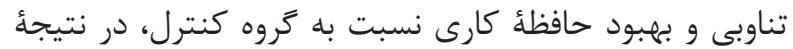

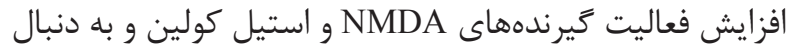

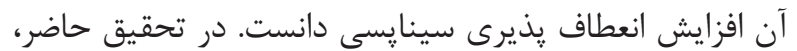

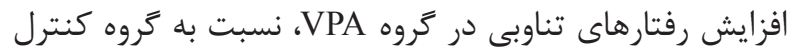

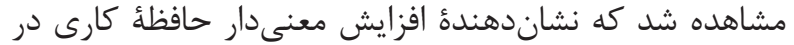

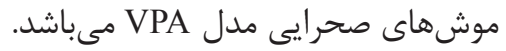

از طرفى مىتوان عنوان كرد كه احتمالاً اثرات ايیى زنتيكى

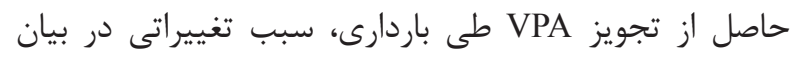

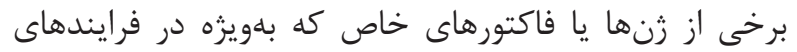

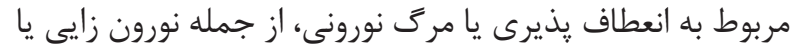

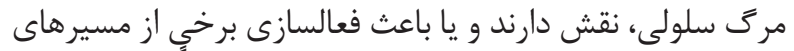

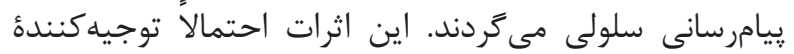

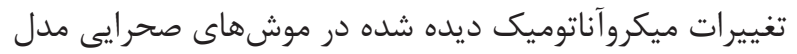

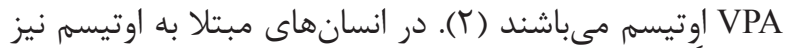

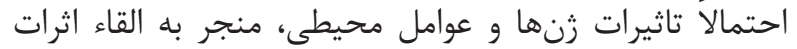

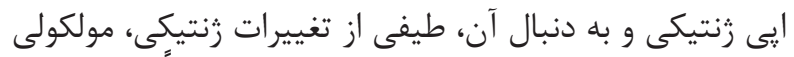

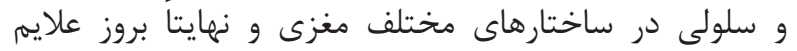

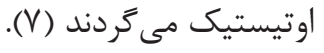

نوروتروفينها تنظيم كنندههاى اصلى تكوين، رشد ور و تمايز

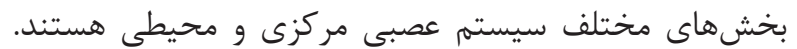

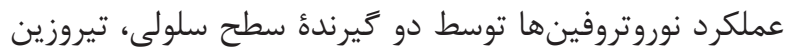

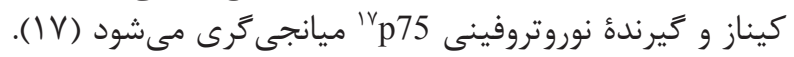

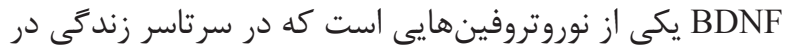
قشر انتورينال توليد مىشود و ونى داراى اثرات تروفيك در در رشد

${ }^{10}$ Autism spectrum disorder

${ }^{11}$ Oxidative stress

${ }^{12}$ Fragile $\mathrm{X}$ syndrome

${ }^{13}$ Tuberous sclerosis

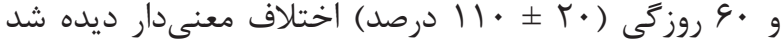

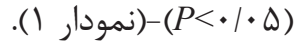

آزمون بيوشيميايى

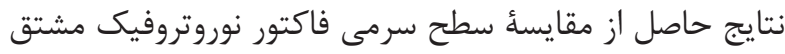

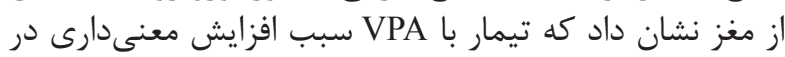

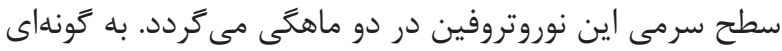

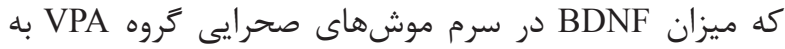

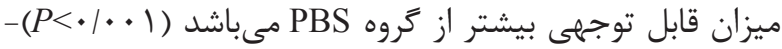

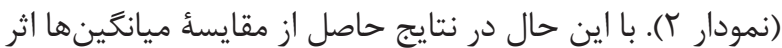

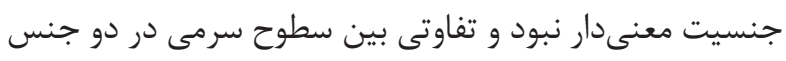

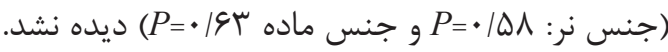

$$
\text { بحث و نتيجه كيرى }
$$

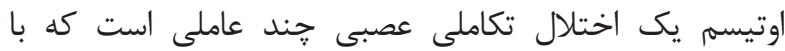

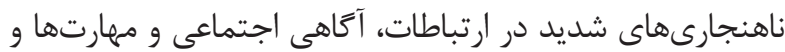

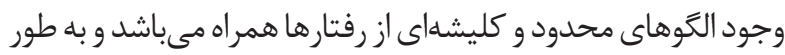

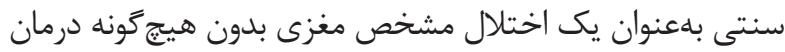

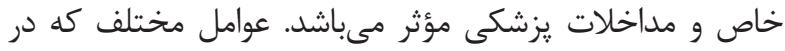

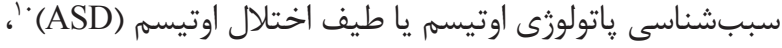

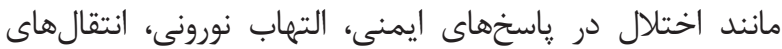

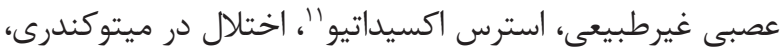

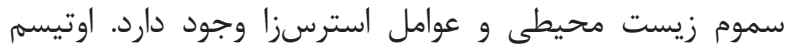

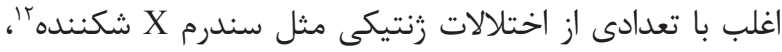

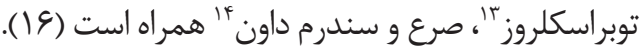

از طريق مهار يراكسيداسيون خربىها و اكسيداسيون

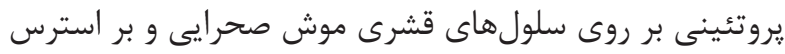

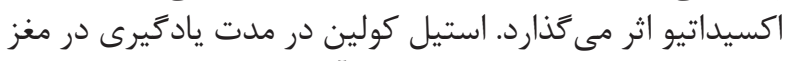

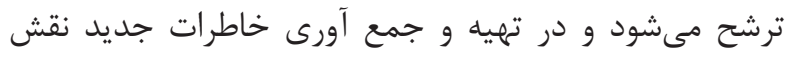

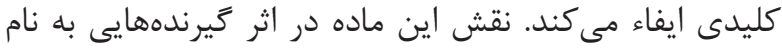

${ }^{14}$ Down syndrome

${ }^{15} \mathrm{~N}$-methyl-d-aspartate receptor

${ }^{16}$ Rats autistic

${ }^{17}$ Neurotrophin receptor $\mathrm{p} 75$ 
افزايش اولية فعاليت BDNF، ممكن است نقش سببشناسى

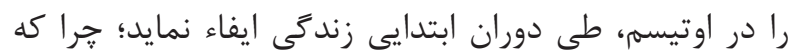

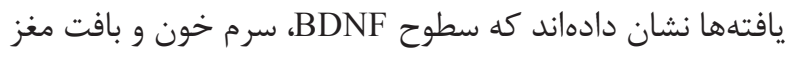

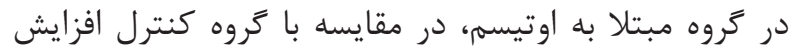

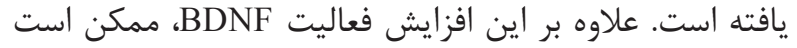

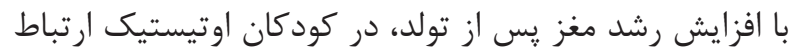
داشته باشد ( • (广).

در مطالعه حاضر نيز، بررسى سطوح سرمى BDNF در كروه

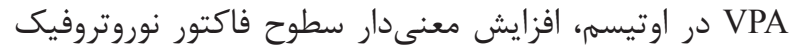

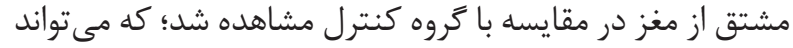

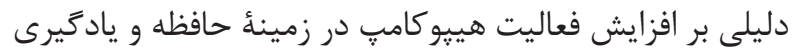

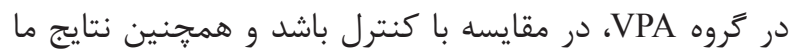

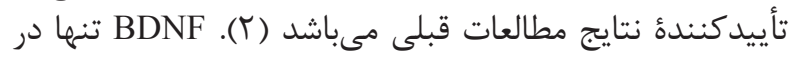

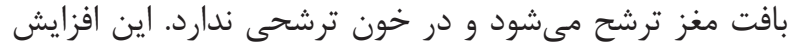

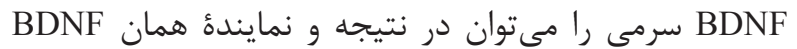

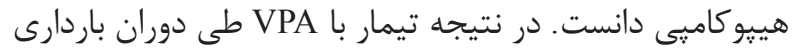

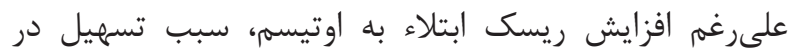
حافظئ كارى به همراه افزايش بيان سرمى إنى

1. Barnes-Holmes D, Miler EC, Canitano R, Moller AR, Destefani V, Murphy C, et al. New autism research developments. New York: Nova Science Publishers, Inc. 2008; p. 1-226.

2. Edalatmanesh MA, Nikfarjam H, Vafaee-Bagheri F, Moghadas M. Increased hippocampal cell density and enhanced spatial memory in the valproic acid rat model of autism. Brain Res. 2013;1526: 15-25.

3. Lazerson A, Hofstadter L, Bloom FE. Brain, mind and behavior. 3th ed. New York: W. H. Freeman and Company. 1985; p. 1-202.

4. McKay SE, Purcell AL, Carew TJ. Regulation of synaptic function by neurotrophic factors in vertebrates and intervertebrates: Implications for development and learning. Learn Mem. 1999; 6 (3): 193-215.

5. Gertner MJ, Thomas SA. The roles of norepinephrine in spatial reference and spatial working memory. CUREJ; 2006; 1-27.

6. Kaplan HJ, Sadock BJ. Synopsis of psychiatry. 8th ed. Baltimore, Williams \& wilkins. 1998; p. 1179-91.

7. Sigman M, Capps L. Children with autism: A developmental perspective. 1st ed. London, Harward University Press. 1997; p. 34-50, 61-70, 73-80, 134-140.
و تكوين سيستم عصبى مىباشد. علاوه بر اثرات تروفيك در

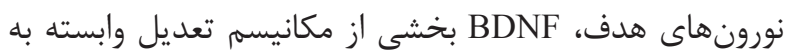

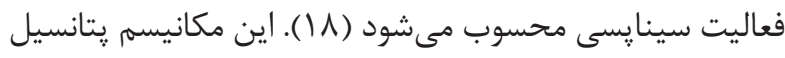

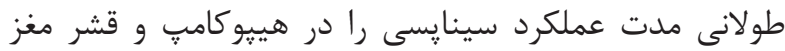

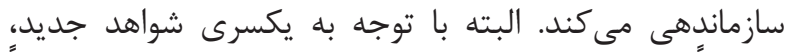

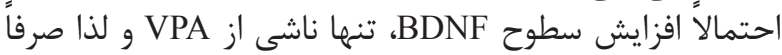

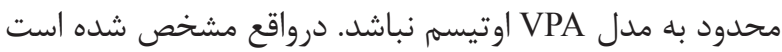

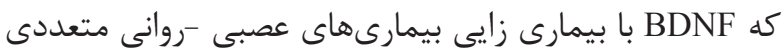

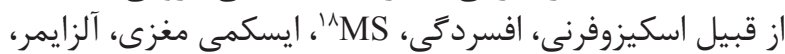

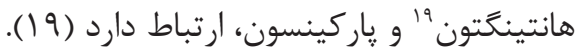

اوتيسم، در بين بيمارىهاى مذكور، تنهها اختلالى است كه

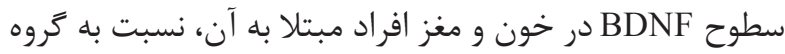

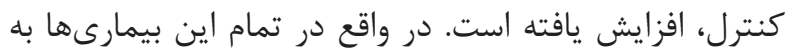

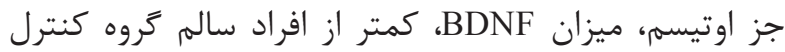

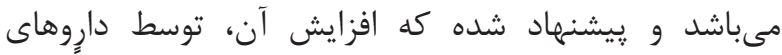

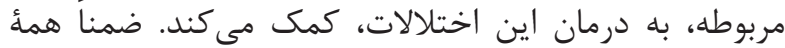

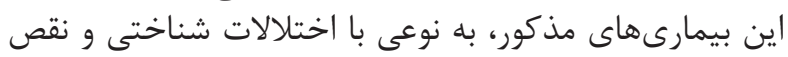

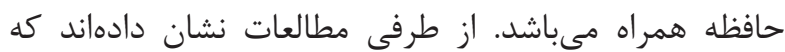

منابع

8. Saul R. Autistic regression and disintegration disorder. Sem Ped Neur. 1998; 2: 248-85.

9. Parmelee D: Child and adolescent psychiatry. 1st ed. U.S.A. Mosby. 1998; 49-68.

10. Barkley RA. The effects of methylphenidate on various types of activity level and attention in hyperkinetic children. J Abnorm Child Psychol. 1977; 5(4): 351-69.

11. Mattson MP, Culmsee C, Yu Z, Camandola S. Roles of nuclear factor kappa $B$ in neuronal survival and plasticity. J Neurochem. 2000; 74(2): 443-56.

12. Monti B, Polazzi E, Contastabile A. Biochemical, molecular and epigenetics mechanisms of valproic acid neuroprotection. Cur Mol Pharmacol. 2009; 2(1): 95-109.

13. Boehme F, Gil-Mohapel J, Cox A, Patten A, Giles E, Brocardo PS, et al. Voluntary exercise induces adult hippocampal neurogenesis and BDNF expression in a rodent model of fetal alcohol spectrum disorders. Eur $\mathrm{J}$ Neurosci. 2011; 33(10): 1799-811.

14. Lee E, Son H. Adult hippocampal neurogenesis and related neurotrophic factors. BMB Rep. 2009; 42(5): 239-44.

\footnotetext{
${ }^{18}$ Multiple sclerosis

${ }^{19}$ Huntington
} 


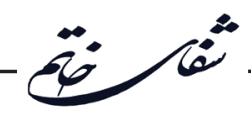

15. Monfils MH, Cowansage KK, LeDoux JE. Brain derived neurotrophic factor: linking fear learning to memory consolidation. Mol Pharmacol. 2007; 72(2): 235-7.

16. Correia CT, Coutinho AM, Sequeira AF, Sousa IG, Lourenço Venda L, Almeida JP, et al. Increased BDNF levels and NTRK2 gene association suggest a disruption of BDNF/TrkB signaling in autism. Genes Brain Behav. 2010; 9(7): 841-8.

17. Pardo CA, Eberhart CG. The neurobiology of autism. Brain Pathol. 2007; 17: 434-47.

18. Kumar B, Prakash A, Sewal RK, Medhi B, Modi M. Drug therapy in autism: a present and future perspective. Pharmacol Rep. 2012; 64(6): 1291-304.

19. Nykjaer A, Willnow TE, Petersen CM. p75NTR-live or let die. Curr Opin Neurobiol. 2005; 15(1): 49-57.

20. Yano H, Chao MV. Mechanisms of neurotrophin receptor vesicular transport. J Neurobiol. 2004; 58(2): 244-57. 